\title{
OS PRINCÍPIOS JURÍDICOS NO ESTADO DEMOCRÁTICO DE DIREITO E O PRINCÍPIO TRABALHISTA DA PROTEÇÃO: UMA ANÁLISE DAS FUNÇÕES INFORMATIVA, NORMATIVA E INTERPRETATIVA DO PRINCÍPIO DA PROTEÇÃO.
}

\section{THE LEGAL PRINCIPLES IN THE DEMOCRATIC STATE OF LAW AND THE LABOR PRINCIPLE OF PROTECTION: AN ANALYSIS OF THE INFORMATIVE, REGULATORY AND INTERPRETATIVE FUNCTIONS OF THE PRINCIPLE OF PROTECTION.}

\begin{abstract}
Nilson Feliciano de Araújo ${ }^{1}$ Marcia Coser Petri

“O princípio de proteção se refere ao critério fundamental que orienta o Direito do Trabalho, pois este, ao invés de inspirar-se num propósito de igualdade, responde ao objetivo de estabelecer um amparo preferencial a uma das partes: o trabalhador."

Américo Plá Rodriguez
\end{abstract}

\section{RESUMO}

Este artigo tem por escopo investigar, a partir da perspectiva das dimensões materiais e eficaciais do direito ao trabalho, abordando a questão dos princípios e suas funções, a abrangência do princípio da proteção no direito do trabalho. Promovendo o aprofundamento investigativo através de pesquisa descritivo-explicativa do tipo documental-bibliográfica, dedica-se a problemas analítico-conceituais das teorias dos princípios. Revela que os princípios têm ampla aplicação no direito do trabalho e estes, especialmente o da proteção, devem estar presentes no sistema trabalhista em suas funções informativa, interpretativa e normativa a fim de assegurar-se a eficácia dos direitos fundamentais sociais.

Palavras Chaves: direito do trabalho; funções; princípios; proteção; trabalho.

\begin{abstract}
This article aims to investigate, from the perspective of the material and effective dimensions of the right to work, addressing the issue of principles and their functions, the comprehensiveness of the principle of protection in labor law. Promoting the deepening of research through a descriptive-explanatory research of the documentary-bibliographic type, is
\end{abstract}

\footnotetext{
${ }^{1}$ Mestrando em direito pela Universidade do Oeste de Santa Catarina - Chapecó-SC, Santa Catarina, (Brasil). Professor nos cursos de Direito e Pós-Graduação da UNOESC, Campus de Videira-SC e Joaçaba-SC (Brasil). E-mail: nilson.araujo@ unoesc.edu.br

${ }^{2}$ Mestranda em direito pela Universidade do Oeste de Santa Catarina - Chapecó-SC, Santa Catarina, (Brasil). Assessora Jurídica e Professora no curso de Direito da UNOESC, Campus de Videira-SC (Brasil). E-mail: marcia.petri@ unoesc.edu.br
} 
dedicated to analytical-conceptual problems of theories of principles. It reveals that the principles have broad application in labor law and these, especially protection, must be present in the labor system in its informative, interpretative and normative functions in order to ensure the effectiveness of fundamental social rights.

Keywords: labor law; Functions; Principles; Protection; job.

\section{INTRODUÇÃO}

O presente artigo tem por escopo investigar, a partir da perspectiva das dimensões materiais e eficaciais do direito fundamental ao trabalho, abordando a questão dos princípios jurídicos no Estado democrático de direito e suas funções e abrangência, bem como as funções informativa, interpretativa e integrativa, do princípio da proteção, e seus desdobramentos, no âmbito do direito do trabalho.

Partindo-se das percepções acerca dos princípios jurídicos de Norberto Bobbio, Robert Alexy e Ronald Dworkin, que evidenciam a relevância do papel dos princípios em um determinado ordenamento jurídico, pois inspiram o legislador na criação da norma, suprem as lacunas da lei e são utilizados na interpretação das regras positivadas, trazendo harmonia ao sistema jurídico, trata-se, no presente artigo, assim, de resgatar a fundamentalidade do princípio da proteção no âmbito do direito do trabalho, sobretudo quando posta em questão a sua aplicabilidade na solução dos casos concretos, verificando-se como os princípios, no Estado democrático de direito, são utilizados como ferramenta de efetivação de direitos fundamentais, notadamente em relação ao princípio da proteção, de aplicabilidade no direito do trabalho, destacando-se as funções informativa, normativa e interpretativa do princípio da proteção segundo a teoria de Américo Plá Rodriguez.

Promovendo o aprofundamento investigativo, através de pesquisa descritivoexplicativa do tipo documental-bibliográfica, o presente artigo dedica-se, assim, com principal foco na doutrina, a partir da revisão bibliográfica pertinente, a problemas analítico-conceituais das teorias dos princípios em geral e do direito do trabalho em particular. Destacando, também, as características essenciais do direito do trabalho como ramo autônomo do direito, revela que os princípios têm ampla aplicação no direito do trabalho e estes, e em especial o princípio da proteção, devem estar presentes no sistema jurídico trabalhista não só em suas funções informativa e interpretativa, mas principalmente, em sua função normativa no momento da 
resolução do fato concreto a fim de assegurar-se a eficácia plena de implementação de direitos fundamentais sociais.

\section{OS PRINCÍPIOS JURÍDICOS NO ESTADO DEMOCRÁTICO DE DIREITO E SUAS FUNÇÕES}

Os princípios são proposições básicas que orientam o legislador na criação da lei (função informativa), agem como norma quando não há regulamentação específica (função normativa) e ainda auxiliam o operador do direito na correta interpretação da norma (função interpretativa), de tal sorte que são de extrema importância na organização do ordenamento do Estado democrático de direito e na efetivação de direitos fundamentais.

O estudo, compreensão e aplicação correta dos princípios jurídicos é um tema que há tempos instiga os filósofos teóricos do direito, pois as teorias dos princípios são de extrema relevância tanto quando se trata de lançar luzes sobre o fundamento ético e moral do direito moderno, quanto quando se trata de sua utilização concreta pelos tribunais na aplicação dos direitos do ponto de vista técnico do operador jurídico na análise do fato concreto e na aplicação de uma regra jurídica à solução do conflito (GUALUPPO, 1999, p. 1).

Os Estados democráticos de direito sempre deverão estar pautados na observância dos direitos fundamentais, de modo a assegurar a efetividade desses direitos, ditos fundamentais, a todos os cidadãos, proporcionando a devida segurança jurídica. Os princípios jurídicos exercem um papel de extrema relevância em qualquer Estado minimamente civilizado, na medida em que estabelecem preceitos básicos do ordenamento jurídico como pressuposto e concomitante mecanismo de efetivação de direitos mínimos - fundamentais -, pautados na dignidade humana e, assim, devidos a qualquer ser humano.

A evolução social, as novas tecnologias e a globalização romperam as barreiras físicas das fronteiras, de forma que hoje os Estados, com as comunidades políticas, jurídicas e sociais que o conformam, não estão mais fechados ao mundo externo, seja pela facilidade de interação entre os povos, seja pela necessidade que um Estado tem de estabelecer relações comerciais como forma de prover as necessidades econômicas e culturais de seus cidadãos. Nessas relações reguladas por organismos internacionais, destacam-se alguns princípios jurídicos que deverão ser seguidos pelos Estados como referentes de sua legitimidade em termos políticos e jurídicos, inclusive para que possam fazer parte de certo bloco político ou econômico.

Assim, algumas vezes muito mais por pressão externa ou conveniência política ou econômica do que por outros motivos, os Estados menos democráticos vão paulatinamente 
inserindo em sua cultura e em seu ordenamento jurídico a observância a alguns princípios fundamentais de direito. Com o passar do tempo, o povo tente a exigir do Estado a efetivação desses direitos e a partir da pressão social incorporam-se definitivamente determinados direitos no âmbito dos Estados. Essa é uma das inúmeras contribuições que o princípio propicia na difusão e na implementação de direitos fundamentais.

Após inseridos no ordenamento jurídico de um Estado, os princípios estabelecem balizamentos sobre os quais o jurista deve exercer sua criatividade e razoabilidade, ponderando os termos, de forma a poder aplicar com equidade a justiça ao caso concreto (BARROSO, 1998, p. 256).

\subsection{Os princípios segundo Norberto Bobbio}

Norberto Bobbio, em sua obra clássica “A Era dos Direitos”, trouxe profunda contribuição ao estudo filosófico dos direitos fundamentais do homem, fomentando os debates doutrinários sobre a origem, os fundamentos dos direitos humanos e a forma com que se dá a efetivação desses direitos.

Os direitos humanos são desejáveis e merecem ser perseguidos, sobretudo enquanto não houver o reconhecimento pleno de todos esses direitos. Contudo, o reconhecimento só virá quando se encontrar o fundamento que os justificar. É nesse sentido que o estudo e o aprofundamento do debate sobre o tema poderá proporcionar uma melhor justificação para a aplicação e efetivação dos direitos fundamentais (BOBBIO, 2004, p. 15-16).

Embora os direitos humanos não necessitem obrigatoriamente de norma positivada, vê-se que, quando há preceito legal regulamentando, a efetivação dos direitos ocorre mais rapidamente, não demandando maiores discussões em relação à implementação dessas garantias mínimas, que são inerentes a qualquer ser humano, embora sejam, ainda, de difícil reconhecimento em alguns Estados, mesmo os democráticos, em virtude de fatores sociais, políticos, culturais e econômicos.

Segundo Bobbio, os direitos do homem podem ser tratados sob várias perspectivas, dentre as quais destacam-se a filosófica, a histórica, a ética, a jurídica e a política. Em sua abordagem, Norberto Bobbio trata desses direitos sob a perspectiva da filosofia da história, analisando os fatos históricos e a sua influência na evolução dos direitos humanos (BOBBIO, 2004, p. 50). 
Ao longo da história, muitos fatos se tornaram importantes e decisivos para o progresso da humanidade, trazendo significativa contribuição à evolução dos povos, consubstanciando, inclusive, datas comemorativas, que são até hoje reverenciados por todos os que se incursionam na pesquisa dos direitos fundamentais da pessoa humana.

Um marco histórico decisivo e importante na evolução dos direitos fundamentais foi a Declaração dos Direitos do Homem e do Cidadão, aprovada pela Assembleia Nacional Francesa em agosto de 1789, marcando o fim de uma era e o início de outra. Em seguida, intensos debates se promoveram, surgindo nesse momento histórico uma consciência política em torno da necessidade de preservação dos direitos humanos, tendo o tema assumido novas proporções a partir dessas incipientes discussões, suscitando um olhar mais atento de alguns filósofos e crítico de outros (BOBBIO, 2004, p. 79).

A Declaração Universal dos Direitos do Homem, aprovada pela Assembleia Geral das Nações Unidas em dezembro de 1948, é, para Bobbio, um marco histórico em relação aos direitos fundamentais, já que os fundamentos dos direitos humanos estão enunciados nessa carta, que representa certo consenso acerca dos direitos mínimos inerentes aos seres humanos, para que possam viver com um núcleo mínimo de direitos fundamentais e, assim, possam, todos, dispor da dignidade em sua plenitude (BOBBIO, 2004, p. 26).

Para Bobbio (2004, p. 203), embora esses fatos históricos tenham trazido significativos avanços ao conceito e à efetivação dos direitos humanos, os direitos do homem estão atrelados a - e dependentes de - dois problemas principais: a paz e a democracia. Não subsiste nenhum direito em qualquer Estado sem que essas duas situações estejam plenamente resolvidas e em harmonia. Prossegue, assim, Bobbio, ressaltando que:

Direitos do homem, democracia e paz são três momentos necessários do
mesmo movimento histórico: sem direitos do homem reconhecidos e
efetivamente protegidos não existe democracia, sem democracia não existem
as condições mínimas para a solução pacífica dos conflitos que surgem entre
os indivíduos, entre grupos e entre grandes coletividades tradicionalmente
indóceis e tendencialmente autocráticas que são os Estados, apesar de serem
democráticas com seus próprios cidadãos (BOBBIO, 2004, p. 203).

Para Bobbio, os princípios gerais são apenas normas fundamentais, ou generalíssimas do sistema, ou seja, normas gerais que atuam indistintamente acima e entre as normas comuns, regulamentando direitos, posição essa que é divergida por outros filósofos, que defendem uma área mais ampla de atuação dos princípios, não só como normas, mas, principalmente, como base de sustentação de todo o ordenamento jurídico de um Estado democrático de direito. 
Em sua obra "Teoria da Norma Jurídica", Bobbio considera o direito como um conjunto de normas ou regras de conduta que regulam nossa vida desde o momento em que nascemos até a morte. São inúmeras regras - e muitas das quais sequer têm percebida a sua existência, dada a automaticidade e cotidianidade do nosso comportamento -, que regulam desde as coisas mais triviais até as situações mais complexas da vida em sociedade. Essas regras têm por objetivo influenciar e controlar os comportamentos de indivíduos e grupos, direcionando-os para certos objetivos, de acordo com a conveniência daqueles que produziram o regramento (BOBBIO, 2001, p. 24-26).

Bobbio adere à corrente de filósofos positivistas na medida em que dá ênfase à norma que esteja inserida no ordenamento jurídico de um Estado, com diretrizes específicas e até comandos expressos, certamente preocupado com a efetivação e a concretização dos comandos normativos e a sua real eficácia na regulação de direitos. Nessa linha, Bobbio dá uma praticidade maior aos princípios gerais de direito, tendo-os não somente como um fundamento norteador de um sistema jurídico, mas, principalmente, como verdadeira norma, atuando diretamente na regulação de relações jurídicas concretas.

A par dessas bem fundadas razões e da preocupação com a efetividade das normas e dos princípios, não se pode relevar a um segundo plano a extrema importância que os princípios têm também em suas funções informativa e interpretativa, já que essas características é que tornam os princípios fonte de criação e de interpretação de normas, consubstanciando importante ferramenta de regulação das relações sociais em um Estado democrático de direito.

Os princípios jurídicos em sua função informativa são a base que sustenta a essência de um Estado democrático de direito, e quando fixados proporcionam a criação de normas que assegurarão a ideia e/ou o valor neles estabelecidos, sendo uma diretriz obrigatória ao legislador no momento da criação de novas leis, servindo como fonte inspiradora na construção da norma jurídica positivada.

Quanto à função interpretativa que é atinente aos princípios, também é significativa sua relevância para proporcionar os ajustes necessários no momento da aplicação da norma ao caso concreto, traduzindo-se o princípio, assim, também em instrumento de equidade e razoabilidade na distribuição da justiça, de modo a possibilitar ao julgador o exercício pleno da ponderação e da adequação de certa regra a um fato específico, dando assim mais possibilidade à efetivação da justiça e de direitos, já que mesmo em um Estado democrático de direito nem sempre há leis que assegurem o exercício pleno de direitos, possibilitando-se assim a utilização dos princípios para dar os contornos necessários à regra, de forma que esta cumpra a sua função 
social de garantir aos membros de um Estado o pleno acesso aos direitos assegurados, mesmo através dos princípios.

\subsection{Os princípios segundo Robert Alexy}

Robert Alexy é um dos filósofos mais influentes da era moderna. Sua obra "Teoria dos Direitos Fundamentais" tem suscitado acirrados debates entre os que estudam os direitos humanos, sendo um autor utilizado como parâmetro em diversas pesquisas que envolvem a análise de aplicabilidade de direitos fundamentais e a colisão de princípios fundamentais.

Alexy desenvolve sua pesquisa teórica a partir da análise dos direitos fundamentais na Constituição alemã e segundo as decisões do Tribunal Constitucional Federal alemão, buscando, através de um raciocínio lógico e de uma fórmula que atribui pesos a princípios, analisar o confronto entre princípios e sugerir que os tribunais, sempre que analisarem essa potencial colisão, o façam com critérios mais objetivos de forma a evitar decisões discrepantes em relação a casos semelhantes, o que gera insegurança jurídica e descrédito nos tribunais em sua missão de pacificação social.

Robert Alexy faz a distinção de três dimensões da ciência ou dogmática jurídica, a saber: analítica, empírica e normativa. Na dimensão analítica, Alexy analisa os conceitos primários de norma e direitos subjetivos, construções jurídicas e exame da estrutura do sistema jurídico, finalizando com a análise e sopesamento dos direitos fundamentais. Na dimensão empírica, observa o conhecimento das leis e sua análise nos tribunais, bem como a efetividade do direito quando for condição para sua validade. Por fim a dimensão normativa se funda na verificação da decisão correta no caso concreto, utilizando-se a norma positivada (ALEXY, 2008, p. 32-36).

Prossegue Alexy apontando a diferença entre regra e princípio, destacando que ambos são normas na medida em que dão comandos do que deve ser feito. A distinção entre eles se dá através do critério da generalidade, pelo qual os princípios são normas com um grau de generalidade alto, e as regras com um grau de generalidade relativamente baixo, ou seja, mais especificas que os princípios (ALEXY, 2008, p. 86).

Vale dizer, então, que os princípios são mais genéricos e abrangentes e atuam de forma mais indeterminada, expressando comandos com maior grau de subjetividade, sendo tidos como mandados de otimização contendo comandos mais amplos, podendo ser cumpridos de várias formas, dentro de possibilidades jurídicas e reais existentes e na medida do possível. Já as regras têm conteúdo mais específico e objetivo, direcionado à regulação de situações pontuais, esmiuçando minudentemente os comandos de forma a regular o fato social com maior grau de 
proximidade, gerando maior obrigatoriedade no seu cumprimento, inclusive estabelecendo sanções específicas em caso de descumprimento (ALEXY, 2008, p. 90).

Nos casos de colisão entre princípios e conflitos entre regras é possível verificar com mais clareza a diferença entre princípios e regra. Quando duas regras se conflitam, uma delas deixa de prevalecer ou é tornada inválida, pois são comandos específicos e se aplicam direta e objetivamente ao caso concreto, não havendo possibilidade de flexibilidade de uma regra em detrimento de outra. Já na colisão de princípios, tal situação não ocorre porque, diferentemente da regra, um princípio, por conter preceitos genéricos, jamais será totalmente invalidado por outro. O que ocorre é a momentânea prevalência de um sobre o outro em determinadas circunstâncias, podendo, em outras, a situação até se inverter integralmente (ALEXY, 2008, p. 92-94).

Ressalte-se que é justamente essa colisão de princípios o ponto central da teoria de Robert Alexy, quando busca afastar a subjetividade na análise de fatos em que haja colisão de princípios. Para isso, utiliza-se da fórmula do peso para avaliar quando, no caso concreto, um princípio deve prevalecer sobre o outro. Aos princípios aplicam-se pesos tendo-se em consideração o fato concreto. A partir desse sistema de pesos é aplicada a fórmula do peso para se calcular qual princípio prevalecerá sobre o outro naquele fato específico, de forma concreta.

Alexy traz em sua obra vários casos julgados pelo Tribunal Federal alemão, explicando a sua teoria aplicada aos casos concretos, sopesando o valor de cada princípio e justificando a prevalência de um sobre o outro em determinado caso concreto. Argumenta que sua teoria recebe severas críticas, por propor fórmulas matemáticas para resolver conflitos jurídicos relevantes provenientes da colisão de princípios. Discorda, contudo, das críticas, destacando que não se trata de operações matemáticas, mas sim de raciocínio lógico e objetivo na valoração de princípios através de pesos e, a partir daí, da aplicação da referida fórmula para se verificar o valor numérico de cada um dos princípios, e para que, consequentemente, se identifique que princípio prevalecerá sobre outro naquele caso em análise.

A par da justificativa de Alexy, para retirar a subjetividade das decisões dos tribunais quando analisam colisões de princípios, verifica-se que sua teoria também tem relativa subjetividade no momento de se fixar o valor dos pesos dos princípios em conflito, já que não há critérios objetivos nesse momento, sendo os pesos fixados em razão da compreensão pessoal de cada um, não havendo um balizamento confiável e objetivo neste momento.

Destaque-se que, após a aplicação dos pesos, a fórmula irá possibilitar o cálculo e apontará o resultado final, que poderá estar comprometido caso os pesos não tenham sido 
apontados corretamente, não restando afastada, assim, integralmente a subjetividade pretendida; a par disso, a teoria de Alexy demonstra-se muito importante no sopesamento da colisão de princípios em conflito, como tem sido reconhecido pela doutrina atualmente.

\subsection{Os princípios segundo Ronald Dworkin}

Dworkin conceitua princípio como um padrão mínimo a ser observado por ser o princípio - uma exigência de justiça, equidade e moralidade, inobstante podendo também assegurar uma situação econômica, política ou social considerada desejável (DWORKIN, 2002).

Assim, destaca que a diferença entre princípio e regra jurídica é de natureza lógica, porquanto as regras são aplicadas de forma binária, tudo ou nada, ou seja, quando uma regra vige, outra que esteja em conflito com ela deixa de valer, de modo que uma anula a outra. Já os princípios são aplicados mediante ponderações acerca de valores, onde um não anula o outro, mas o sobrepõe apenas momentaneamente, de forma a prevalecer num dado momento e ser afastado em parte em outro momento. Uma regra, para não ser aplicada, precisa ser totalmente descartada, enquanto um princípio será apenas confrontado com outros princípios e aplicado ou não depois de um juízo de ponderação, não sendo, jamais, invalidado (DWORKIN, 2002, p. 36).

Dworkin trata da problemática da aplicação dos princípios no direito estadunidense, que é fundado na regra e nos julgamentos dos tribunais, criticando a discricionariedade do juiz e a possibilidade de o magistrado produzir regras que serão utilizadas como parâmetros em julgamentos. Ressalta que devem existir princípios com maior e menor importância, e que esses princípios deverão nortear as decisões dos tribunais, não podendo as decisões ficarem exclusivamente subordinadas às preferências pessoais do juiz.

Por isso, defende a segurança jurídica e o estabelecimento de critérios mais objetivos para a fundamentação das decisões do juiz, destacando que os princípios se traduzem em uma importante fonte de direitos, sendo um balizamento mais objetivo e confiável que pode ser utilizado indistintamente, trazendo maior objetividade - e, assim, maior imparcialidade - nas decisões dos tribunais quando se analisa direitos que não estão expressamente regulamentados

por normas jurídicas. É nesse momento que o princípio pode ser utilizado como regra em sua função normativa, preenchendo as lacunas da lei e adequando-se ao caso concreto de forma a resolver o conflito social. 
Essa força normativa dos princípios fica mais evidenciada quando não há, no ordenamento jurídico, ou na jurisprudência, regramento claro e suficiente à motivação da decisão no caso concreto, devendo, nesses casos, os princípios ser utilizados com força de norma e, assim, na promoção concreta da solução do conflito.

Assim, Dworkin é enfático em destacar a importância dos princípios jurídicos, notadamente em sua função normativa, como forma de afastar-se a subjetividade dos órgãos julgadores e, também, a discricionariedade do juiz, possibilitando-se que as decisões judiciais estejam em harmonia com os preceitos básicos da sociedade em um Estado democrático de direito.

\section{UMA SÍNTESE: AS FUNÇÕES INFORMATIVA, NORMATIVA E INTERPRETATIVA DOS PRINCÍPIOS}

Os princípios em um ordenamento jurídico são as bases pelas quais será construído todo o direito positivado. Neles estão expressos os preceitos fundamentais de um Estado, seja em sua constituição formal, seja também em relação aos preceitos morais, culturais e de justiça que eles - os princípios - contêm e que nortearão todo o sistema jurídico de um povo, dando um sentido de unidade ao ordenamento, estabelecendo as principais características de uma Nação.

Princípios são um feixe de ideias de proposições fundamentais que se formam na consciência das pessoas e dos grupos sociais a partir de certo contexto, e que possibilitam a compreensão da realidade sob a ótica de um objetivo maior a ser compartilhado por um povo. São compostos de experiências decorrentes das práticas e vivências cotidianas e de uma visão do mundo que se busca para a vida harmónica em uma coletividade de pessoas. São, portanto, o reflexo e a informação das experiências individuais e coletivas em um determinado ambiente (DELGADO, 2007, p. 184).

As funções dos princípios têm sido tema muito debatido tanto pelos principais filósofos que tratam de direitos fundamentais, como também pelos legisladores e operadores do direito, já que são apontados como o próprio ponto central para a compreensão de um sistema jurídico. Diferentemente das regras, que são mais específicas, os princípios são orientações gerais e, assim, de uma aplicabilidade bem mais ampla em um sistema jurídico, o que comprova a relevância de suas funções. 
Os princípios estão presentes na primeira ideia de concepção de um Estado, já na sua origem, definindo qual é o projeto sob o qual se alicerceará a estrutura estatal e como serão as relações entre esse Estado com seu povo - o pacto social instituinte -, e também com os demais Estados que fazem parte de sua cadeia de relações. Em um segundo momento, os princípios são também muito importantes na medida em que agem como normas positivadas, cumprindo assim uma função de verdadeira norma (jurídica), regulando situações específicas e dando aos julgadores fundamentos para a efetivação da justiça em cada caso concreto. Por fim, os princípios também servem como fonte de interpretação das normas já positivadas, possibilitando a análise das regras à luz de um objetivo maior, de uma ideia maior e geral que está inserta nos princípios básicos de uma Nação.

É cediça, na doutrina, a existência das funções informativa, normativa ou subsidiária e interpretativa dos princípios, como também a importância deles na organização e funcionamento de um Estado, pois traçam um balizamento seguro que sinaliza os fins e objetivos supremos de uma Nação, a forma com que ela identifica e resolve seus problemas sociais, políticos e econômicos a partir do ordenamento.

\section{O TRABALHO, O DIREITO DO TRABALHO E SEUS PRINCÍPIOS}

O trabalho teve início no momento em que o homem não mais optou por esperar que os recursos naturais ou atos divinos lhe provessem o alimento e a subsistência. Quando o ser humano teve que buscar o alimento e sentiu necessidade de proteção contra os outros animais que habitavam a terra, viu-se na situação de construir habitação e cultivar seu alimento, dando origem ao trabalho.

No princípio, o trabalho era realizado apenas para ocasiões momentâneas e para atender necessidades básicas e essenciais de cada indivíduo, de modo que, no momento em que cessasse a origem da necessidade, o trabalho deixava de ser realizado. Mais adiante, com a evolução da humanidade e o aumento da população, foram surgindo grandes povoados e a necessidade de produção de bens e serviços, passando o trabalho, que era integralmente manual e individual, a ter auxílio de máquinas e a ser realizado em linhas de produção, situação que perdura até os dias atuais, agora com implemento da informática e robótica nas atividades produtivas.

Hoje o trabalho se materializa como um aspecto da dignidade da pessoa humana, sendo um dos predicados que distinguem o homem dos outros animais, alterando a realidade das coisas, transformando tanto a natureza externa no ambiente social em que o trabalhador está 
inserido, quanto interna e íntima do próprio ser humano, tratando-se de um elemento central do desenvolvimento da sociabilidade humana. O trabalho não é só uma fonte de enriquecimento material, mas sobretudo moral, na medida em que cria sonhos e perspectivas de realização pessoal aos quais não se pode dar uma mensuração econômica (SCHWARZ, 2011, p. 1).

Com a evolução do trabalho surge também o direito do trabalho como forma de regulamentar esta tempestuosa relação entre o capital e o trabalho. Fonte de intensos conflitos e confrontos, o direito do trabalho foi se implementando nos ordenamentos jurídicos dos Estados em razão dessas tensões sociais entre as classes de empregados e empregadores, onde o Estado se obrigava a intervir para reestabelecer a paz social e, assim, propunha normas para a regulação das relações trabalhistas, em um primeiro momento através de leis e, mais adiante, alcançando tal regulação um status constitucional, de direito fundamental.

Delgado (2007, p. 88) afirma que o direito do trabalho surgiu da combinação de três grupos específicos de fatores: econômicos, sociais e políticos. Os fatores econômicos decorrem do incremento do processo produtivo através da indústria, que fomentou o trabalho subordinado e movimentou a classe de trabalhadores e empregadores na produção de bens e serviços, gerando riqueza aos Estados. Os fatores sociais foram a concentração do proletariado em grandes cidades industriais, e a identificação profissional dos trabalhadores em torno da empresa. Por fim, os fatores políticos decorrem da intervenção da sociedade e do Estado, no sentido de normatizar as relações de trabalho e assegurar direitos - e segurança jurídica, portanto - aos empregados e empregadores.

Sendo um ramo autônomo do direito, o direito do trabalho tem regras, institutos, princípios e fontes próprios, que o identificam e o diferenciam dos demais ramos do direito.

As fontes do direito do trabalho são materiais e formais, sendo as primeiras consubstanciadas pelo fato social decorrente das lutas entre as classes de trabalhadores e empregadores, decorrendo as segundas - as formais - das fontes materiais na medida em que são as normas positivadas que surgiram justamente em razão desses confrontos e da necessidade de intervenção do Estado na regulação destas relações.

Quanto aos tipos de princípios do direito do trabalho, podem ser identificados os gerais, aplicáveis também ao direito do trabalho, e os princípios específicos do direito do trabalho, que o caracterizam e o distinguem. Os gerais são aqueles que são aplicáveis aos demais ramos do direito, mas também podem ser usados no direito do trabalho. Já os específicos são os próprios do direito do trabalho e já forjados segundo as características inerentes às próprias relações empregatícias. 
Segundo Schwarz (2011, p. 29), os princípios são aplicados de forma subsidiária e são meios que auxiliam na interpretação e aplicação da lei, preenchendo suas lacunas, determinando o real sentido e alcance da norma, sendo essa a sua função integradora e interpretativa. Além dessas funções, outra não menos importante é a função informadora que já é reconhecida pela doutrina e jurisprudência, a qual serve de inspiração ao legislador na criação da norma, de forma que ela esteja em total harmonia com os princípios de um determinado ramo do direito.

Tanto na doutrina quanto na jurisprudência, não há um consenso acerca do rol de princípios gerais de direito que são aplicáveis ao direito do trabalho. Da mesma forma, não há efetivo consenso, exaustivo, quanto aos princípios específicos do direito do trabalho. Contudo, alguns princípios gerais do direito e outros específicos do direito do trabalho já se consolidaram entre os autores trabalhistas e também são recepcionados pela jurisprudência nas decisões dos tribunais.

$\mathrm{Na}$ enumeração dos princípios gerais de direito aplicáveis ao direito do trabalho, podem ser, assim, identificados: o princípio da dignidade da pessoa humana, constante do art. $1^{\circ}$, inc. III, da Constituição; o princípio da não discriminação (arts. $2^{\circ}, \mathrm{IV}$, e $5^{\circ}$, caput e inc. I, da Constituição); o princípio da razoabilidade e boa-fé; e o princípio da irreversibilidade das conquistas e garantias sociais (SCHWARZ, 2011, p. 29-33).

Quanto aos princípios específicos ou peculiares ao direito do trabalho, há certo consenso acerca do princípio da proteção, o qual, para alguns doutrinadores, é o único princípio inerente ao direito do trabalho, dele derivando outras especificidades que são chamadas de peculiaridades do direito do trabalho. Entretanto, outros princípios também são mencionados na doutrina e jurisprudência, como os princípios da irrenunciabilidade, o princípio da continuidade, o princípio da primazia da realidade, o princípio da razoabilidade, o princípio da boa-fé, o princípio da norma mais favorável ao trabalhador, o princípio da manutenção da condição mais favorável ao trabalhador, o princípio da imperatividade das normas trabalhistas, o princípio da indisponibilidade de direitos.

Considerando que alguns princípios se assemelham ou são derivações de outros, propomos a abordagem, dentre os que enumeramos, de alguns princípios, reconhecidos pela doutrina e pela jurisprudência, mais relevantes na categorização e distinção do direito do trabalho, que consubstanciam o próprio núcleo fundamental do direito do trabalho, e são imprescindíveis para o conhecimento do sistema trabalhista.

\subsection{Princípio da proteção}


O princípio da proteção é o principal de todos os princípios peculiares ao direito do trabalho e nele estão, de certa forma, inseridos todos os demais, já que são derivados desse preceito maior, que é a proteção que o direito do trabalho dispensa ao trabalhador, tido como a parte mais vulnerável da relação de trabalho.

O princípio da proteção fundamenta-se nessa posição desfavorável em que o trabalhador se põe perante o empregador, já que, quando há escassez de emprego no mercado de trabalho, a tendência é que haja por parte do empregado abdicação de direitos em troca de empregabilidade. Em sentido contrário, o poder econômico representado pelo empregador, quando há sobra de mão de obra, também irá se utilizar deste descompasso na lei de oferta e procura para impor ao empregado a renúncia a direitos em troca do emprego. Dessa forma, e diante deste quadro estrutural desfavorável na relação capital/trabalho, emerge a necessidade de intervenção estatal na ordem econômica e social e no mercado de trabalho para impor freios aos ímpetos que levem à exploração do trabalho (SCHWARZ, 2011, p. 34).

\subsection{Princípio da irrenunciabilidade de direitos}

O princípio da irrenunciabilidade trata da imperatividade das normas trabalhistas, que impede que o empregado renuncie a direitos, retirando do obreiro a prerrogativa de dispor do seu direito incondicionalmente. Esse princípio também está inserido na redação do art. $9^{\circ}$ da Consolidação da Leis do Trabalho - CLT, cuja redação é a seguinte: "Serão nulos de pleno direito os atos praticados com o objetivo de desvirtuar, impedir ou fraudar a aplicação dos preceitos contidos na presente Consolidação".

Rodriguez (2000, p. 142), ao tratar desse princípio, ressalta que a irrenunciabilidade é "a impossibilidade jurídica de privar-se voluntariamente de uma ou mais vantagens concedidas pelo direito trabalhista em benefício próprio".

\subsection{Princípio da continuidade}

O princípio da continuidade consiste na presunção que milita em favor do trabalhador, de que é do seu interesse manter íntegro o contrato individual de trabalho, porquanto é do fruto desse contrato que provém o seu sustento e subsistência.

Esse princípio também decorre de uma característica especial do contrato de trabalho, que é de trato sucessivo, onde, a cada período, se implementam condições e são cumpridas obrigações, fechando-se um ciclo de obrigações recíprocas (o empregado trabalha no mês, 
cumprindo sua principal obrigação contratual, e, ao final, o empregador, em contrapartida, paga o salário pactuado).

Assim, por esse princípio, é do empregador o ônus da prova em comprovar o término do contrato individual de trabalho quando há comprovação de prestação de serviço pelo empregado.

\subsection{Princípio da primazia da realidade}

O princípio da primazia da realidade, ou do contrato realidade, significa que, em havendo discordância entre o que efetivamente ocorre na prática e o que provém dos documentos, deve-se dar preferência ao que realmente ocorreu no campo dos fatos, desprezando-se as formalidades (RODRIGUEZ, 2000, p. 339).

A aplicabilidade desse princípio se dá na medida em que gera presunção relativa, em favor do empregado, da existência do próprio contrato de trabalho, como contrato-realidade, quando comprovada a prestação pessoal de serviço, cabendo ao empregador, quando alegar a inexistência do fato presumido, a prova em sentido contrário. Assim, havendo dúvida sobre a natureza da relação jurídica entre o prestador e tomador de serviço, tem-se a presunção de que é relação de emprego, cabendo ao tomador do serviço a prova de desconstituição dessa suposta relação empregatícia (SCHWARZ, 2011, p. 43).

\subsection{Princípio da razoabilidade e da boa-fé}

O princípio da razoabilidade se funda na afirmação essencial de que o ser humano deve proceder conforme orienta a sua razão e ter uma conduta baseada na equidade e no bom senso.

É aplicável na área comportamental do ser humano, naquelas situações em que a norma não pode prescrever critérios muito rígidos, tampouco prever as circunstâncias possíveis, deixando uma ampla margem de discricionariedade, situação que gera um terreno fértil para possível desvio de finalidade de aplicação da norma jurídica, sendo o princípio da razoabilidade uma ponderação que se faz em relação à aplicação do que se entende como justo (RODRIGUEZ, 2000, p. 392-393).

Já a boa-fé não é um princípio ou requisito especial do contrato de trabalho, mas algo imprescindível a todos os ramos do direito, notadamente nas relações contratuais, em que há o acordo de vontades, sendo requisito para a validade do negócio jurídico que as partes se conduzam sempre com lealdade e boa-fé.

\subsection{Princípio da norma mais favorável ao trabalhador}


Inobstante ser tratada por Rodriguez (2000) como um subprincípio, ou seja, um desdobramento do princípio da proteção, o princípio da norma mais favorável ao trabalhador tem sido considerado pela doutrina e pela jurisprudência trabalhista como um dos mais relevantes princípios, que distingue o direito do trabalho dos demais ramos do direito, na medida em que afasta a hierarquia formal das normas para, na vigência simultânea de duas regras aplicáveis ao mesmo fato, no âmbito da relação de emprego, aplicar-se a que seja mais favorável ao empregado.

Na aplicação do princípio, deve-se verificar o conteúdo de cada norma, a coletividade de trabalhadores abrangidos e que o confronto das normas ocorra de forma concreta, ou seja, indagando-se se a norma inferior é, na situação fática, mais ou menos favorável ao empregado (RODRIGUEZ, 2000, p. 127).

Também as teorias da acumulação e do conglobamento explicam a forma como se deve identificar, dentre duas normas, a que seja mais favorável ao trabalhador. Pela primeira, havendo dois textos normativos aplicáveis ao mesmo caso concreto, retira-se de cada um deles o que for mais benéfico ao empregado, sem, contudo, anular-se um texto em desfavor de outro. Já pela teoria do conglobamento, examina-se cada norma na sua totalidade e verifica-se qual delas é a mais benéfica no todo, aplicando-se somente uma por inteiro e afastando-se a outra completamente (SCHWARZ, 2011, p. 36-37).

Enquanto a aplicação do princípio da norma mais favorável é inquestionável nos meios doutrinários e jurisprudenciais trabalhistas, a forma de sua aplicação é fruto de intensos debates em torno das duas teorias, tendo prevalecido adeptos da teoria do conglobamento, embora com sérias divergências.

\section{O PRINCÍPIO DA PROTEÇÃO E SUAS FUNÇÕES INFORMATIVA, NORMATIVA E INTERPRETATIVA SEGUNDO AMÉRICO PLÁ RODRIGUEZ}

O princípio da proteção é um dos principais fundamentos do direito do trabalho e, de forma concomitante, o seu principal princípio. É na compreensão das características e da aplicabilidade do princípio da proteção que se pode conhecer a dinâmica que envolve o estudo e a aplicação concreta do direito do trabalho.

No direito comum, há uma preocupação em assegurar-se a igualdade jurídica entre as partes contratantes, que, na maioria das vezes, estão em condições de igualdade na relação contratual, ao menos em termos jurídicos. No direito do trabalho, em razão dessa desigualdade jurídica e econômica - fática e estrutural - existente entre as partes do contrato de trabalho, há 
a preocupação central de se proteger o trabalhador tido como a parte vulnerável dessa relação - desigualdade jurídica -, objetivando-se com isso o reestabelecimento da verdadeira igualdade entre as partes (RODRIGUEZ, 2000, p. 127).

A condição de desigualdade do trabalhador, que é o alicerce do princípio da proteção, decorre de vários fatores sociais, políticos e econômicos dentro de um sistema capitalista, que deixa o trabalhador em situação de fragilidade perante o empregador, notadamente quando a oferta de emprego é menor que a demanda, evidenciando-se o desequilíbrio dessa lei e possibilitando-se ao poder econômico fazer prevalecer sua vontade, nas situações em que for contratar com o trabalhador.

Essa posição desfavorável do trabalhador no contrato de trabalho se dá desde antes da formação da relação jurídica contratual entre as partes e se estende após seu término, abrangendo assim direitos e obrigações pré e pós contratuais, já que o trabalho é para o trabalhador a única fonte de subsistência, e o obreiro tende a lutar pela manutenção dessas condições mínimas de vida. Já para o empregador, a mão de obra é uma mercadoria que faz parte de um processo complexo de produção, onde a mão de obra é somente um dos fatores de produção e que pode ser facilmente substituído por novas tecnologias de produção, o que, em certos momentos, torna a mão de obra descartável. Por isso essa grande preocupação em se efetivar certa proteção ao obreiro, de modo que se possa frear o ímpeto do empreendedor em relação ao trabalhador (SCHWARZ, 2011, p. 34-35).

Diante da diferença entre as partes na relação contratual trabalhista, justifica-se a existência de mecanismos que possam reestabelecer um equilíbrio para possibilitar que os interesses da parte mais forte não prevaleçam sobre a mais fraca, de modo a afastar-se a coação e o vício de consentimento que desvirtuam as relações contratuais. Importante esclarecer que não é só no direito do trabalho que há mecanismos que protegem uma parte em detrimento da outra. No direito do consumidor, usado exemplificativamente, também há uma proteção ao consumidor diante do fornecedor, comerciante ou fabricante, sendo estabelecidos princípios e regras jurídicas para evitar que o poder econômico prevaleça sobre os direitos individuais dos consumidores.

Assim, inobstante alguns questionamentos e posições contrárias de alguns, os princípios protetivos são de aceitação no direito em geral, e utilizados como forma de se estabelecer a verdadeira igualdade entre as partes quando há a supremacia de uma sobre a outra parte em uma relação contratual privada. No direito do trabalho, o princípio da proteção segue essa linha, sendo amplamente reconhecido tanto na doutrina quanto na jurisprudência. 
Rodriguez (2000, p. 107) subdivide o princípio da proteção em três feixes distintos: in dubio pro operário, norma mais favorável e condição mais benéfica. Pelo princípio in dubio pro operario, entre os vários sentidos de uma norma, busca-se aquele mais favorável ao trabalhador. Pelo princípio da norma mais favorável, quando se está diante de mais de uma regra aplicável, deve-se optar por aquela mais favorável ao empregado, mesmo fugindo dos critérios clássicos da hierarquia das normas. Por fim, na aplicação da condição mais benéfica ao trabalhador, não se pode ter reduzidas as condições mais favoráveis que se consolidaram no contrato de trabalho, estando essa regra também certa consonância com o princípio geral do não retrocesso social.

Ao par do reconhecimento da existência e da validade dos princípios gerais e dos específicos do direito do trabalho, há também intenso debate acerca da abrangência, utilização e limites quanto à aplicação desses princípios no ordenamento jurídico, inobstante sejam reconhecidos como fonte de direito e sejam admitidas suas funções informativa, normativa e interpretativa.

Os princípios são "linhas diretrizes que informam algumas normas e inspiram direta ou indiretamente uma série de soluções, pelo que podem servir para promover e embasar a aprovação de novas normas, orientar a interpretação das existentes e resolver os casos não previstos" (RODRIGUEZ, 2000, p. 36).

Os princípios do direito do trabalho são mais que uma fonte do direito, uma vez que seu alcance ultrapassa a função de fonte de direito, e os situa em outro plano, pois estão presentes muito antes da criação da regra, bem como na sua elaboração, aplicação e interpretação, constituindo-se verdadeiras premissas básicas necessárias a todo ordenamento jurídico trabalhista.

A função informativa dos princípios juslaboralistas é possível de ser verificada tanto na doutrina quanto, principalmente, nas exposições de motivos das leis que regulamentam a relação de trabalho, estando, em muitas situações, também explícitas no próprio texto legal, onde se denota a presença dessas diretrizes, conforme dispõe, por exemplo, o art. $8^{\circ}$ da Consolidação das Leis do Trabalho:

Art. $8^{\circ}$ - As autoridades administrativas e a Justiça do Trabalho, na falta de disposições legais ou contratuais, decidirão, conforme o caso, pela jurisprudência, por analogia, por equidade e outros princípios e normas gerais de direito, principalmente do direito do trabalho, e, ainda, de acordo com os usos e costumes, o direito comparado, mas sempre de maneira que nenhum interesse de classe ou particular prevaleça sobre o interesse público. 
Parágrafo único - $\mathrm{O}$ direito comum será fonte subsidiária do direito do trabalho, naquilo em que não for incompatível com os princípios fundamentais deste.

Art. 481 - Aos contratos por prazo determinado, que contiverem cláusula assecuratória do direito recíproco de rescisão antes de expirado o termo ajustado, aplicam-se, caso seja exercido tal direito por qualquer das partes, os princípios que regem a rescisão dos contratos por prazo indeterminado. (grifei)

A função normativa e interpretativa dos princípios também é verificada nas decisões dos tribunais, que, ao apreciarem o caso concreto e diante das lacunas da lei, utilizam-se dos princípios do direito do trabalho tanto como fonte subsidiária da lei, quanto também para interpretá-la e dar os contornos adequados da subsunção (ao fato), utilizando-se da ponderação e da equidade.

É o que se verifica na análise da jurisprudência consolidada do Tribunal Superior do Trabalho, pelas súmulas e orientações jurisprudenciais, onde os princípios estão presentes em muitas decisões, sendo utilizados como fonte tanto nas omissões quanto na interpretação das leis, como se verifica, por exemplo, a partir da Súmula $n^{\circ} 212$, que menciona o princípio da continuidade da relação de emprego; da Súmula $n^{\circ} 248$, que nega a invocação do direito adquirido ao adicional de insalubridade, mencionando também a questão da inexistência de ofensa ao princípio da irredutibilidade salarial; da Súmula $\mathrm{n}^{\circ} 372$, que faz menção ao princípio da estabilidade financeira; da Súmula $n^{\circ} 408$, que faz referência expressa ao princípio "iura novit curia" (ninguém se escusa de cumprir a lei, alegando que não a conhece); da Súmula ${ }^{\circ}$ 421, que se reporta aos princípios da fungibilidade e da celeridade processual; e da Súmula $\mathrm{n}^{\circ}$ 451, que trata do princípio da isonomia.

É inegável que, no sistema justrabalhista, os princípios são de extrema importância em todos os momentos, desde a criação das normas jurídicas à sua aplicação e interpretação. Os princípios de direito do trabalho são preceitos básicos que caracterizam esse ramo do direito e servem de balizamento aos que nele incursionam, de forma que tenham o conhecimento, o sentido e a amplitude da norma trabalhista, para que possam melhor interpretá-la e aplicá-la.

\section{CONCLUSÕES}

Os direitos humanos, na atualidade, têm sido objeto de estudo e de implementação e de efetivação em todo o mundo globalizado. A efetivação desses direitos nos Estados democráticos de direito também é um dos principais objetivos dos organismos internacionais e dos próprios Estados, que buscam difundir, nas mais variadas culturas, a implementação de 
direitos mínimos inerentes aos seres humanos, para que as pessoas sejam respeitadas em sua dignidade.

Os princípios são essenciais em um ordenamento jurídico na medida em que estabelecem os fundamentos iniciais de um Estado, criando as condições de existência e efetividade dos direitos fundamentais, e possibilitando a difusão desses preceitos e direitos para grande parte da humanidade, que, por razões culturais, políticas ou econômicas, não tem acesso a esses direitos básicos.

Destaca-se a importante contribuição que filósofos trouxeram ao conhecimento dos direitos humanos, dentre eles Robert Alexy, Ronad Dworkin e Norberto Bobbio, além de outros, que aprofundaram a discussão sobre a importância dos princípios nos Estados democráticos de direito e também sobre a própria necessidade de implementação dos direitos humanos, seja através de norma positivada ou da eficácia normativa dos princípios.

No estudo das obras desses importantes autores e do conhecimento de suas teorias, os princípios jurídicos tiveram grande exposição, o que obrigou pesquisadores e operadores do direito a buscarem conhecer as funções dos princípios e as formas com que eles são inseridos nos sistemas jurídicos.

A aplicação dos princípios no direito do trabalho também é objeto de intensos debates nos meios doutrinários e jurisprudenciais, tendo-se em Américo Plá Rodriguez um dos principais ícones no estudo dos princípios de direito do trabalho, sendo seguido por muitos outros doutrinadores brasileiros, convertendo-se em uma fonte obrigatória de consulta nesse ramo do direito.

Por ter características próprias, o direito do trabalho também tem seus princípios específicos, e o princípio da proteção é um dos seus principais fundamentos, sendo o seu mais importante princípio. É na compreensão das características e da aplicabilidade do princípio da proteção que se pode conhecer a dinâmica que envolve o estudo e a aplicação concreta do direito do trabalho.

As funções informativa, interpretativa e integrativa dos princípios têm sido amplamente utilizadas no direito do trabalho, fazendo parte do sistema jurídico em todo o processo, desde a criação das leis, à sua aplicação e interpretação, o que trouxe significativos avanços na efetivação de direitos sociais no Brasil. 


\section{REFERÊNCIAS}

ALEXY, R. Teoria dos direitos fundamentais. São Paulo: Malheiros, 2008.

BARROSO, L. R. Interpretação e aplicação da Constituição. São Paulo, Saraiva, 1998.

BOBBIO, N. Teoria do ordenamento jurídico. Brasília: UNB, 1996

A era dos direitos. Rio de Janeiro: Elsevier, 2004.

BONAVIDE, R. S. Conceito de princípios constitucionais. São Paulo: Revista dos Tribunais, 1999.

DELGADO, M. G. Curso de direito do trabalho. São Paulo: LTr, 2007

DWORKIN, R. O império do direito. São Paulo: Martins Fontes, 2003.

Levando os direitos a sério. São Paulo: Martins Fontes, 2002.

ESPÍNDOLA, R. S. Conceitos de princípios constitucionais. São Paulo: Revista dos Tribunais, 1999.

GUALUPPO, M. C. Os princípios jurídicos no Estado democrático de direito: ensaio sobre o modo de sua aplicação. Revista de Informação Legislativa, Brasília, n. 143, jul./set. 1999.

RODRIGUEZ, A. P. Princípios de direito do trabalho. São Paulo: LTr, 2000.

SCHWARZ, R. G. Curso de iniciação ao direito do trabalho. Rio de Janeiro: Elsevier, 2011. 